\title{
Phosphodiesterase inhibitors for the treatment of pulmonary hypertension
}

\author{
M.R. Wilkins*, J. Wharton*, F. Grimminger" ${ }^{\#}$ and H.A. Ghofrani\#
}

ABSTRACT: The pulmonary vascular bed is both a source of and target for a number of vasoactive factors. Among the most important for pulmonary vascular homeostasis are factors that utilise cyclic guanosine monophosphate (cGMP) as an intracellular second messenger. These include nitric oxide and the natriuretic peptide family (atrial, brain and C-type natriuretic peptides). In the search for therapeutic strategies that engage the cGMP signalling pathway for the treatment of pulmonary arterial hypertension (PAH), inhibition of cGMP metabolism by phosphodiesterase type 5 (PDE5)-targeted compounds has proven most successful to date. One PDE5 inhibitor, sildenafil, has been shown to improve pulmonary haemodynamics and exercise capacity in patients with PAH and is now an approved treatment. Others are under investigation.

An interesting, although still tentative, observation is the potential of sildenafil to reduce pulmonary vascular resistance without adversely affecting ventilation-perfusion matching. Another is the expression of phosphodiesterase type 5 in the hypertrophied right ventricle. These data suggest that phosphodiesterase type 5 inhibitors may have effects that distinguish them from other treatments for pulmonary hypertension and merit further study.

KEYWORDS: Cyclic guanosine monophosphate, hypertension, phosphodiesterase inhibition, pulmonary

\section{THE CYCLIC GUANOSINE}

MONOPHOSPHATE SIGNALLING PATHWAY

Nitric oxide (NO) is a highly reactive molecule synthesised from L-arginine by NO synthases (NOS): endothelial (eNOS), inducible (iNOS) and neuronal. Studies in knockout mice indicate that eNOS-derived NO is the principle mediator of endothelium-dependent vasodilation in the pulmonary circulation, but both eNOS and iNOS play a role in chronic modulation of basal tone [1]. NO diffuses into vascular smooth muscle cells, where it stimulates cyclic guanosine monophosphate (cGMP) production from soluble guanylyl cyclase (fig. 1).

The natriuretic peptides interact with specific cell membrane receptors [2]. Two subtypes of natriuretic peptide receptor (NPR), NPR-A and NPR-B, are transmembrane guanylyl cyclases (particulate guanylyl cyclases), where the extracellular domain binds atrial natriuretic peptide (ANP), brain natriuretic peptide (BNP) or C-type natriuretic peptide and the intracellular domain hydrolyses guanosine triphosphate (GTP) to cGMP.

Increasing evidence suggests that the intracellular distribution of cGMP is not uniform, but rather is compartmentalised within cells, and this may underlie the differential effects of cGMP generated by soluble and particulate guanylyl cyclases [3]. The diverse effects of stimulating cGMP production in cardiovascular tissues are dependent on its binding to at least three groups of proteins: cGMPdependent protein kinase (or protein kinase-G; PKG), cGMP-regulated phosphodiesterases (PDEs) and cyclic nucleotide-gated ion channels

Previous articles in this series: No. 1: Dupuis J, Hoeper MM. Endothelin receptor antagonists in pulmonary arterial hypertension. Eur Respir $\mathrm{J} 2008$; 31 : 407-415. No. 2: Gomberg-Maitland M, Olschewski H. Prostacyclin therapies for the treatment of pulmonary arterial hypertension. Eur Respir J 2008; 31: 891-901. No. 3: Behr J, Ryu JH. Pulmonary hypertension in interstitial lung disease. Eur Respir J 2008; 31: 1357-1367.

AFFILIATIONS

*Experimental Medicine and

Toxicology, Imperial College London, Hammersmith Hospital, London, UK. ${ }^{\#}$ Medical Clinic II/N, Dept of Internal Medicine, University Hospital Giessen and Marburg, Giessen, Germany.

CORRESPONDENCE

M.R. Wilkins

Experimental Medicine and

Toxicology

Imperial College London

Hammersmith Hospital

Du Cane Road

London

W12 0NN

UK

Fax: 442083831963

E-mail: m.wilkins@imperial.ac.uk

Received:

September 202007

Accepted after revision:

March 102008

STATEMENT OF INTEREST Statements of interest for all authors of this study can be found at www.erj.ersjournals.com/misc/ statements.shtml 


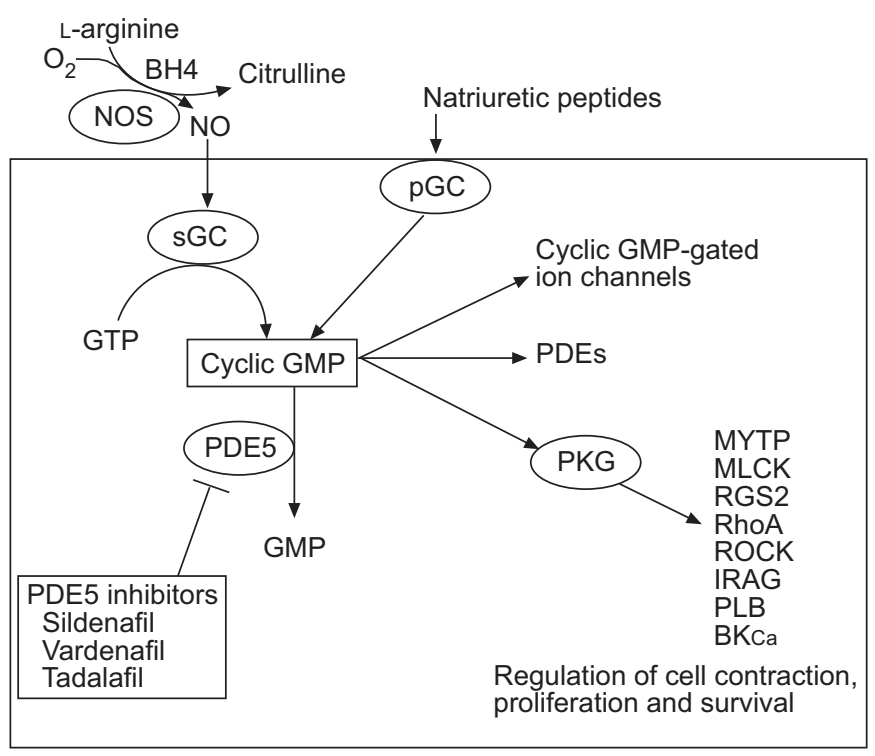

FIGURE 1. Schematic diagram of the nitric oxide (NO)-cyclic guanosine monophosphate (GMP) signalling pathway. NO is synthesised from L-arginine by NO synthases (NOS) with the cofactor tetrahydrobiopterin (BH4). In vascular smooth muscle cells, NO interacts with soluble guanylyl cyclase (sGC) to convert guanosine triphosphate (GTP) to cyclic GMP, which is hydrolysed and inactivated by phosphodiesterase type 5 (PDE5). Functions of cyclic GMP include the regulation of cation channels and PDEs and activation of cyclic GMP-dependent protein kinase (PKG). Activation of PKG results in the regulation of several downstream targets, including myosin phosphatase targeting subunit (MYPT), myosin light chain kinase (MLCK), regulator of G-protein signalling (RGS)2, RhoA, Rho kinase (ROCK), inositol 1,4,5-triphosphate receptor-associated PKG substrate (IRAG), phospholamban (PLB) and calcium-sensitive potassium channels (BKCa). PGC: particulate guanylyl cyclases

[4]. PKG is the most important of these intracellular mediators, whereas the cGMP-regulated PDE type 5 (PDE5) is mainly responsible for modulating intracellular cGMP levels and PKGdependent signalling produced by $\mathrm{NO}$ and natriuretic peptides [5-7]. In addition to being hydrolysed by PDE5, cGMP and its downstream mediator PKG also modulate the activity of this enzyme. Thus, cGMP binding affinity and hydrolysis are increased by PKG-induced phosphorylation of PDE5 [8]. Binding of cGMP to the so-called GAF-A (cGMP-activated PDEs, adenocyclase and Fh1A) domain also promotes phosphorylation of PDE5 and increases catalytic activity $[9,10]$. In addition to these feedback mechanisms, there is the potential for gene regulation, as the promoter region of human PDE5 contains sites responsive to cyclic nucleotides [11, 12].

\section{CGMP AS A REGULATOR OF PULMONARY VASCULAR HOMEOSTASIS}

The pivotal role of the cGMP pathway in regulating pulmonary vascular tone is evident from pharmacological and genetic manipulation of this pathway in vitro and in vivo. For example, mice deficient in eNOS, GTP cyclohydrase-1 (the rate-limiting enzyme in tetrahydrobiopterin synthesis, a cofactor for $\mathrm{NO}$ production) or dimethylarginine dimethylaminohydrolase (the enzyme responsible for metabolising endogenous NOS inhibitors) have all been reported to exhibit pulmonary hypertension $(\mathrm{PH})$ in a normally oxygenated atmosphere [13-15], while mice lacking NPR-A showed an exaggerated response to hypoxia [16]. There have been occasional conflicting reports [17]. Significantly, inhibition of NO production in humans using $N^{\mathrm{G}}$-monomethyl-L-arginine, a competitive antagonist of NOS, resulted in an increase in pulmonary vascular resistance $[18,19]$.

In addition to regulating pulmonary vascular tone, it is also evident that cGMP levels influence pulmonary vascular structure directly, through effects on vascular smooth muscle proliferation and survival. Studies with human distal pulmonary vascular smooth muscle cells in culture have shown that elevation of cGMP, through stimulation of soluble guanylyl cyclase or by inhibition of its breakdown, inhibits serumstimulated proliferation and promotes apoptosis [20].

Studies in humans have indicated that $\mathrm{PH}$ is associated with reduced endogenous NO production. Measurements of NO in exhaled breath were lower in patients with idiopathic pulmonary arterial hypertension (IPAH) than in healthy controls [21]. Histological examination of human lung samples has shown reduced expression of eNOS in pulmonary vessels from IPAH patients compared with healthy lung, although eNOS is well represented in plexiform lesions [22]. Studies in subjects at altitude have suggested that increasing or maintaining NO production in the lung is important for attenuating hypoxia-induced $\mathrm{PH}$; those less able to do so are at most risk of developing $\mathrm{PH}$ [23]. In contrast, circulating ANP and BNP levels are elevated in all forms of $\mathrm{PH}$, a consequence of pressure overload on the right ventricle and atrium stimulating the synthesis and release of these peptides [24-26]. This is a compensatory response, an attempt to reduce workload on the right heart by reducing pulmonary vascular resistance, but the magnitude of this endogenous response is insufficient to counteract the disease process. Finally, increased levels and reduced catabolism of asymmetric and symmetric dimethylarginines, known to be potent endogenous inhibitors of NOS, may contribute to $\mathrm{PH}$ in patients suffering from pulmonary vascular disorders $[27,28]$.

\section{PDE EXPRESSION IN THE LUNG}

In total, 11 PDE families have been identified, which vary in substrate affinity, selectivity and regulatory mechanisms [29]. Of these enzymes, PDE5, -6 and -9 are highly selective for cGMP, PDE1, -2, and -11 bind cGMP and cyclic adenosine monophosphate (cAMP) with equal affinity, and PDE3 and -10 are cGMP-sensitive but cAMP-selective. In the pulmonary circulation, PDE5 and -1 have attracted the most interest by virtue of their tissue distribution.

PDE5 mRNA is widely expressed in human tissues, but is most abundant in the lung and in pulmonary vascular smooth muscle cells [30]. Three splice variants have been identified (PDE5A1, PDE5A2 and PDE5A3), which encode proteins with similar cGMP catalytic activities and sensitivities to sildenafil, but distinct N-terminal sequences, and while PDE5A1 and A2 variants occur in most tissues, expression of the smallest splice variant, PDE5A3, seems to be limited to smooth muscle cells [31]. For all three molecular forms of PDE5, immunoreactivity has been demonstrated in lung homogenates and isolated pulmonary vascular smooth muscle cells $[6,31]$. Expression of PDE5 and $\alpha$-smooth muscle actin (SMA) proteins was found to be greater in lung tissues from patients with $\mathrm{PH}$ compared 
with controls [20]. Specifically, expression of the predominant $98 \mathrm{kDa}$ (PDE5A1) and $77 \mathrm{kDa}$ PDE5 isoforms was significantly increased and PDE5 immunoreactivity colocalised with $\alpha$-SMA in cells in intimal lesions and neomuscularised distal vessels, as well as in smooth muscle cells in the medial layer of the diseased pulmonary vasculature. These findings are consistent with an increase in PDE5 expression, as well as muscle mass, in the hypertensive pulmonary vasculature, and suggest that PDE5 may represent a marker of vascular remodelling, as well as a potential therapeutic target.

A recent report has extended these findings by demonstrating induction of PDE5 expression in the right ventricles of patients with $\mathrm{PH}$ [32]. PDE5 is normally expressed in the coronary vasculature but not in myocytes. Pressure overload on the myocardium leads to the expression of PDE5 in myocytes. Furthermore, studies in vitro have indicated that PDE5 inhibition enhances contractility of myocardium that expresses the enzyme, suggesting that PDE5 inhibition might directly improve right function in $\mathrm{PH}$.

PDE1 is expressed at low levels in pulmonary tissues under normal conditions [33]. However, recent studies have shown significant upregulation of this enzyme in proliferating pulmonary vasculature, indicating a pathogenic role under disease conditions [33-35]. Interestingly, when analysing PDE1 expression in whole lung tissue homogenates, no significant increase was observed in $\mathrm{PH}$ versus normal control tissue. However, immunohistochemistry, as well as expression analyses from micro-dissected tissue, revealed strong upregulation of PDE1A and PDE1C in pre-capillary pulmonary arterial resistance vessels [33]. In the same study, inhibition of the PDE1 with 8-methoxymethyl 3-isobutyl-1-methylxanthine in animal models of PH improved haemodynamics, right heart hypertrophy and vascular remodelling [33]. Finally, the PDE1-selective inhibitor PI79 inhibited DNA synthesis in proliferating human pulmonary arterial smooth muscle cells in culture. Taken together, these findings indicate that upregulation of PDE1C plays a role in the structural remodelling process underlying severe $\mathrm{PH}$ and, thus, offers a novel therapeutic target. Interestingly, sildenafil, which is the approved PDE5 inhibitor for the treatment of pulmonary arterial hypertension (PAH), in addition to its PDE5 inhibitory capacity also has appreciable effects on PDE1 in clinically relevant dosages.

\section{PDE5 INHIBITORS \\ Pharmacology}

A number of drugs, including dipyridamole and theophylline, inhibit PDE5 as part of their spectrum of pharmacological activity. Three selective PDE5 inhibitors, sildenafil, tadalafil and vardenafil, have been licenced for use in humans and investigated for their effects on the pulmonary circulation. These drugs differ significantly in chemical structure but all inhibit with median inhibitory concentration (IC50) values in the low $\mathrm{nM}$ range: sildenafil 1-9 nM [36-39]; tadalafil 1-7 nM $[37,39,40]$; and vardenafil $0.09-0.8 \mathrm{nM}[37,40-42]$. The effect of sildenafil, tadalafil and vardenafil on other PDEs is shown in table 1 . In brief, sildenafil also inhibits retinal PDE6 at $\sim 10$-fold higher concentrations and shows 80-fold selectivity over PDE1. Vardenafil also inhibits PDE6 (with a four- to 25-fold difference in selectivity) but has no significant effect on other PDEs. Tadalafil has little effect on PDE6 but inhibits PDE11 with a five-fold difference in IC50. Tadalafil, in contrast to sildenafil, has no effect on PDE1c.

\section{Pharmacokinetics of selective PDE5 inhibitors}

Sildenafil absorption is rapid and $\sim 95 \%$ following a single oral dose, although absolute bioavailability is reduced to $\sim 40 \%$ because of first-pass metabolism [43]. The time to maximum concentration (Tmax) in the plasma is $\sim 1 \mathrm{~h}$, but this increases further, by $\sim 60 \mathrm{~min}$, if taken with a high-fat meal, and peak plasma concentration falls by $29 \%$ (with no effect on area under curve). This is most likely a result of delayed gastric emptying. The plasma half-life is $\sim 4 \mathrm{~h}$ but, taking into account the IC50 for inhibition of PDE5 in vitro and the high protein binding of the parent drug, the plasma concentration of sildenafil is maintained above the IC50 for 12-18 h following a 100-mg dose. The main route of clearance is by hepatic metabolism, as expected for a relatively lipophilic drug. The major metabolite is $\mathrm{N}$ desmethylsildenafil. This metabolite has the same PDE specificity as sildenafil but about half the potency, and plasma levels are $\sim 40-50 \%$ of the parent drug $[43,44]$.

Studies with human liver microsomes and microsomes expressing individual human cytochrome P (CYP) enzymes have indicated that $75 \%$ of the metabolism of sildenafil is due to CYP3A4 and the remainder to CYP2C9 [45-47]. These studies predict a significant drug-drug interaction through CYP3A4, and this has been found in practice. Co-administration of potent CYP3A4 inhibitors, such as erythromycin, ketoconazole and saquinavir, results in significant increases

\begin{tabular}{|c|c|c|c|c|c|c|c|}
\hline \multirow[t]{2}{*}{ Sildenafil } & 281 & 3.5 & 37 & 34 & 21300 & 2610 & 2730 \\
\hline & (80) & & (11) & (10) & $(6100)$ & (750) & (780) \\
\hline Vardenafil & 70 & 0.14 & 3.5 & 0.6 & $>30000$ & 580 & 162 \\
\hline \multirow[t]{2}{*}{ Tadalafil } & $>30000$ & 6.74 & 1260 & 1300 & $>100000$ & $>100000$ & 37 \\
\hline & $(>4450)$ & & (187) & (193) & $(>14800)$ & $(>14800)$ & (5) \\
\hline
\end{tabular}

Data are presented as median inhibitory concentration values in $\mathrm{nM}$ (fold selectivity versus PDE5). 
in the peak plasma concentration and area under curve of sildenafil, with no effect on plasma half-life; this is consistent with inhibition of pre-systemic metabolism without effect on elimination. Sitaxentan, a weak CYP3A4 inhibitor in vitro, has little effect on sildenafil levels. Conversely, co-treatment with bosentan, a CYP3A4 inducer, significantly reduces plasma sildenafil levels (by $\sim 50 \%$ ) at therapeutic bosentan doses. Sildenafil is a weak inhibitor of several major drug-metabolising enzymes, but the plasma concentrations reached, even following maximum recommended dosing (100 $\mathrm{mg})$, are unlikely to be clinically important. Nonetheless, competition with co-administered bosentan, through CYP3A4 metabolism, leads to a significant increase in bosentan levels. Modestly increased plasma sildenafil levels are seen in elderly patients (aged $>65 \mathrm{yrs}$ ) and patients with hepatic or severe renal impairment, as a result of reduced drug clearance.

Oral absorption of tadalafil is rapid, with a Tmax in plasma of $\sim 2 \mathrm{~h}$. Bioavailability is $36 \%$, protein binding (principally $\alpha 1-$ acid glycoprotein and albumin) is $94 \%$ and the plasma half-life is $17.5 \mathrm{~h}$. Systemic exposure increases linearly over the daily dose range of $2.5-20 \mathrm{mg}$ and, at steady state ( $\sim 5$ days), plasma levels are 1.6-fold higher than at the start of treatment.

Tadalafil is cleared by oxidative metabolism, mainly by CYP3A4, to a catechol, which then undergoes methylation and glucuronidation. The methyl catechol glucuronide is 13,000-fold less potent for PDE5 than the parent molecule. Plasma tadalafil Tmax and half-life are increased slightly in renal failure. The main metabolite, which is renally excreted, shows a significant increase in half-life with progressive renal impairment $(36 \mathrm{~h}$ in health to $54-77 \mathrm{~h}$ in end-stage disease). CYP3A4 inhibitors reduce tadalafil clearance; for example, therapeutic doses of ketoconazole increase tadalafil area under curve by 4.1-fold and maximum concentration $(\mathrm{C} \max )$ by 1.2 -fold. Studies in vitro predict that tadalafil would not reversibly inhibit the metabolism of other drugs metabolised by the major human CYPs, but has the potential to be a weak mechanism-based inhibitor and an inducer of CYP3A4. However, in clinical studies, tadalafil at 10 and $20 \mathrm{mg}$ had little effect on the clearance of the other CYP3A4 substrates, midazolam and lovastatin [48].

Vardenafil is rapidly absorbed (Tmax $\sim 40 \mathrm{~min}$ ) and metabolised, with a plasma half-life of $\sim 4 \mathrm{~h}$ and an absolute bioavailability of $14.5 \%$ (compared with $40 \%$ for sildenafil and vardenafil). Systemic exposure is linear over the dose range 5$20 \mathrm{mg}$. A high-fat ( $>55 \%$ fat calories) breakfast modestly reduces $\mathrm{Cmax}$ by $18 \%$ and prolongs the Tmax of vardenafil by $\sim 1 \mathrm{~h}$, while a moderate-fat meal ( $30 \%$ fat calories) has no significant effects on vardenafil pharmacokinetics. As with other selective PDE5 inhibitors, the major route of metabolism is via hepatic enzymes, including CYP3A4. The major metabolite, an $N$-desethyl derivative, and other minor metabolites are removed principally by biliary excretion. Co-administration of CYP3A4 inhibitors, such as ritonavir, can affect hepatic metabolism. The $\mathrm{N}$-desethyl derivative is a four-fold less potent inhibitor of PDE5 than its parent compound, contributing $\sim 7 \%$ to the overall efficacy of vardenafil.

\section{PRE-CLINICAL STUDIES}

PDE5 inhibitors inhibit the pressor response to acute hypoxia and the thromboxane antagonist, U46619, in isolated rodent lung preparations [49-52]. Further support for PDE5 as a therapeutic target in $\mathrm{PH}$ is evident from chronic dosing studies in animal models of the condition. The most commonly used are chronic hypoxia-induced and monocrotaline-induced rodent models. These studies show that PDE5 inhibition attenuates the rise in pulmonary artery pressure and vascular remodelling if given before exposure to hypoxia or monocrotaline (preventative strategy) and partially reverses the pathology if given up to 2 weeks after inducing $\mathrm{PH}$ (treatment strategy) [53, 54]. Right ventricular hypertrophy is also reduced and survival improved. Studies in genetically manipulated mice reveal that both eNOS and natriuretic peptides contribute to the therapeutic effects of PDE5 inhibition $[16,52]$.

PDE5 inhibition has also been examined in combination with other treatments. Sildenafil has been combined with beraprost, a prostacyclin analogue [55]. The two drugs were given by oral gavage singly or in combination twice daily for 3 weeks, commencing from the time of administration of monocrotaline. Both drugs attenuated the development of $\mathrm{PAH}$, but the combination of the two drugs had additive effects on plasma cAMP and cGMP, pulmonary haemodynamics and vascular remodelling. In a study of the effect on survival, again combination treatment appeared to be superior, with $100 \%$ survival at 6 weeks, compared with $30 \%$ survival on monocrotaline alone, $90 \%$ when monocrotaline- and sildenafiltreated and $80 \%$ when monocrotaline- and beraprost-treated. The combination of sildenafil and bosentan has also been reported to be superior to either treatment alone in the monocrotaline-treated rat model [56].

\section{CLINICAL PHARMACOLOGY OF SELECTIVE PDE5 INHIBITORS}

Consistent with the vascular distribution of PDE5, systemic administration of PDE5 inhibitors produces measurable effects on the cardiovascular system, coupled with increases in plasma and urinary cGMP levels.

Studies in healthy males have shown that sildenafil, in single doses of 100-200 mg, produces a modest fall in both systolic and diastolic blood pressure; the mean maximum decrease in systolic/diastolic blood pressure was $10 / 7 \mathrm{mmHg}$ at $3 \mathrm{~h}$, returning to baseline by $6 \mathrm{~h}$, with no dose-response relationship [57]. There were no accompanying changes in heart rate or cardiac index. The plasma cGMP area under curve increased by $\sim 50 \%$ from baseline. Reductions in mean systolic blood pressure of $1.4-6.6 \mathrm{mmHg}$ and in mean diastolic blood pressure of $2-4.8 \mathrm{mmHg}$ have been reported with vardenafil in males with erectile dysfunction [58]. In a cross-over study in males with erectile dysfunction, both sildenafil $50 \mathrm{mg}$ and vardenafil $10 \mathrm{mg}$ produced significant reductions in systemic blood pressure. Greater variability in response was noted with vardenafil, with three patients reporting fainting following the first dose [59]. Little change in systemic blood pressure was observed in healthy volunteers treated with tadalafil $20 \mathrm{mg}$ or in males aged $>45$ yrs with erectile dysfunction treated daily for 26 weeks [60]. Co-treatment with other vasodilator agents (nitrates in particular but also doxazosin) augmented the fall in blood pressure $[60,61]$. The effect of nitrates is most likely mediated by enhancing the NO-cGMP pathway $[60,61]$. 
In patients with stable ischaemic heart disease, intravenous infusion of sildenafil (up to $40 \mathrm{mg}$ over $60 \mathrm{~min}$ ) produced small reductions in right atrial pressure, pulmonary arterial occluded pressure and systolic and diastolic systemic arterial pressures at rest, but no change in heart rate [57]. The per cent changes from baseline were $-28 \%$ for right atrial pressure, $-27 \%$ for pulmonary arterial pressure, $-20 \%$ for pulmonary arterial occluded pressure, $-6 \%$ for systolic systemic arterial pressure and $-10 \%$ for diastolic systemic arterial pressure. There was also a small $(7 \%)$ reduction from baseline in cardiac output. Small, but significant, dose-related reductions in standing blood pressure were reported in males with ischaemic heart disease, $2 \mathrm{~h}$ (i.e. at Tmax) after single oral doses (5 or $10 \mathrm{mg}$ ) of tadalafil [60].

During an exercise test performed after a sildenafil infusion (up to $40 \mathrm{mg}$ over $60 \mathrm{~min}$ ), maximum pulmonary arterial occluded pressure and mean pulmonary arterial pressure were reduced by 23 and 19\%, respectively, from the measurements during exercise pre-infusion. Systolic and diastolic systemic arterial pressures both decreased by $6 \%$, cardiac output decreased by $11 \%$ and heart rate was not affected by the sildenafil treatment. In similar patient populations, vardenafil $10 \mathrm{mg}$ and tadalafil $10 \mathrm{mg}$ did not alter exercise treadmill time or time to first awareness of angina, and did not alter blood pressure or heart rate achieved $[62,63]$.

Single 50-mg oral doses of sildenafil have been reported to prevent endothelial dysfunction induced by ischaemia and reperfusion in healthy volunteers [64] and in patients with chronic heart failure [65, 66], when measured using a flowmediated dilation protocol. Administration of $20 \mathrm{mg}$ tadalafil on alternate days for 4 weeks has been reported to improve endothelial function in males with increased cardiovascular risk (10-yr cardiovascular risk $>20 \%$ ) [67]. The effect of sildenafil was blocked by glibenclamide, suggesting that the effect of sildenafil was a result of opening adenosine triphosphate-sensitive potassium channels [64].

The effects of single oral therapeutic and supratherapeutic doses of sildenafil (50 and $400 \mathrm{mg}$ ) and vardenafil (10 and $80 \mathrm{mg}$ ) on the Q-T interval corrected for heart rate $\left(\mathrm{QT}_{\mathrm{c}}\right)$ have been examined in a well-designed study in healthy males [68]. Placebo-corrected mean changes in QTc were calculated by two methods. Mean (range) Fridericia-corrected QTc durations at $1 \mathrm{~h}$ after dose were 8 (6-9) ms for vardenafil $10 \mathrm{mg}$ and 6 (58) $\mathrm{ms}$ for sildenafil $50 \mathrm{mg}$. Individualised QTc values yielded similar trends: 4 (3-6) ms for vardenafil $10 \mathrm{mg}$ and 4 (2-5) ms for sildenafil $50 \mathrm{mg}$. Small increases were noted at the higher dose but the dose-response relationship was very shallow and it was concluded that the small increases in QTc with these PDE5 inhibitors were clinically insignificant.

PDE5 is abundant in platelets and PDE5 inhibition abbrogates platelet aggregation [69, 70]. An effect with sildenafil is detectable at higher doses. Studies in platelet-rich plasma from healthy volunteers have detected prolongation of platelet aggregation time in response to collagen at $1 \mathrm{~h}$ but not at $4 \mathrm{~h}$ following a single 100-mg oral dose [71]. No effect was seen with $50 \mathrm{mg}$. Sildenafil did not inhibit adenosine diphosphateinduced aggregation at either dose.

\section{STUDIES IN PATIENTS WITH PH}

Typical of pharmacological studies in $\mathrm{PH}$, the majority of studies have involved patients with IPAH or PAH associated with connective tissue disease and in World Health Organization (WHO) class III.

\section{Acute effects}

Sildenafil reduces pulmonary vascular resistance in a dosedependent manner when given as a single oral dose [72]. Notably, the vasodilator effects are most pronounced in the pulmonary circulation, compared with the systemic circulation, and at least as strong as with inhaled NO at clinically relevant doses [73, 74]. Moreover, sildenafil increases and prolongs the effects of inhaled iloprost [72, 75].

A comparison of the acute responses to sildenafil, tadalafil and vardenafil suggests that each agent has to be assessed individually, despite their common classification as PDE5 inhibitors [76]. In total, 60 consecutive $\mathrm{PAH}$ patients (New York Heart Association functional class II-IV) were assigned to oral intake of $50 \mathrm{mg}$ sildenafil $(\mathrm{n}=19), 10 \mathrm{mg}(\mathrm{n}=7)$ or $20 \mathrm{mg}$ $(\mathrm{n}=9)$ vardenafil, or $20 \mathrm{mg}(\mathrm{n}=9), 40 \mathrm{mg}(\mathrm{n}=8)$, or $60 \mathrm{mg}(\mathrm{n}=8)$ tadalafil. Haemodynamics and changes in oxygenation were assessed over a subsequent 120-min observation period. All three PDE5 inhibitors caused significant pulmonary vasorelaxation, with maximum effects being obtained after 40-45 min (vardenafil), $60 \mathrm{~min}$ (sildenafil) and 75-90 min (tadalafil). Sildenafil and tadalafil, but not vardenafil, caused a significant reduction in the pulmonary to systemic vascular resistance ratio. Significant improvement in arterial oxygenation (equal to that achieved by NO inhalation) was only noted with sildenafil. It was concluded that the three PDE5 inhibitors differ markedly in their kinetics of pulmonary vasorelaxation (the most rapid effect being achieved by vardenafil), their selectivity for the pulmonary circulation (sildenafil and tadalafil being selective, but not vardenafil), and their impact on arterial oxygenation (improvement with sildenafil only). At the time when the present review was drafted, a large randomised placebo controlled trial assessing the effects of chronic tadalafil treatment in patients with PAH had just completed recruitment (ClinicalTrials.gov Identifier NCT00125918) [77].

\section{Chronic treatment}

Several small single-centre studies have reported beneficial effects from long-term treatment of patients with $\mathrm{PAH}$ with sildenafil [78-81] (tables 2, 3 and 4). One study compared sildenafil treatment with bosentan therapy using cardiac magnetic resonance-based measurements of right ventricular mass as an end-point [80]. There were no significant differences between the two treatments (table 3). Both improved 6-min walk distance but only sildenafil significantly reduced right ventricular mass over the 4-month period of study, an effect accompanied by a reduction in circulating BNP levels. These data are of particular interest in the light of recent reports of the induction of PDE5 expression in the right ventricle in $\mathrm{PH}$ [32] and the finding that sildenafil improves right ventricle function in patients with heart failure complicated by secondary $\mathrm{PH}$ [82].

The landmark study for sildenafil in PH was the Sildenafil Use in Pulmonary Arterial Hypertension (SUPER-1) study [81] (table 4). This study examined 278 patients with symptomatic 


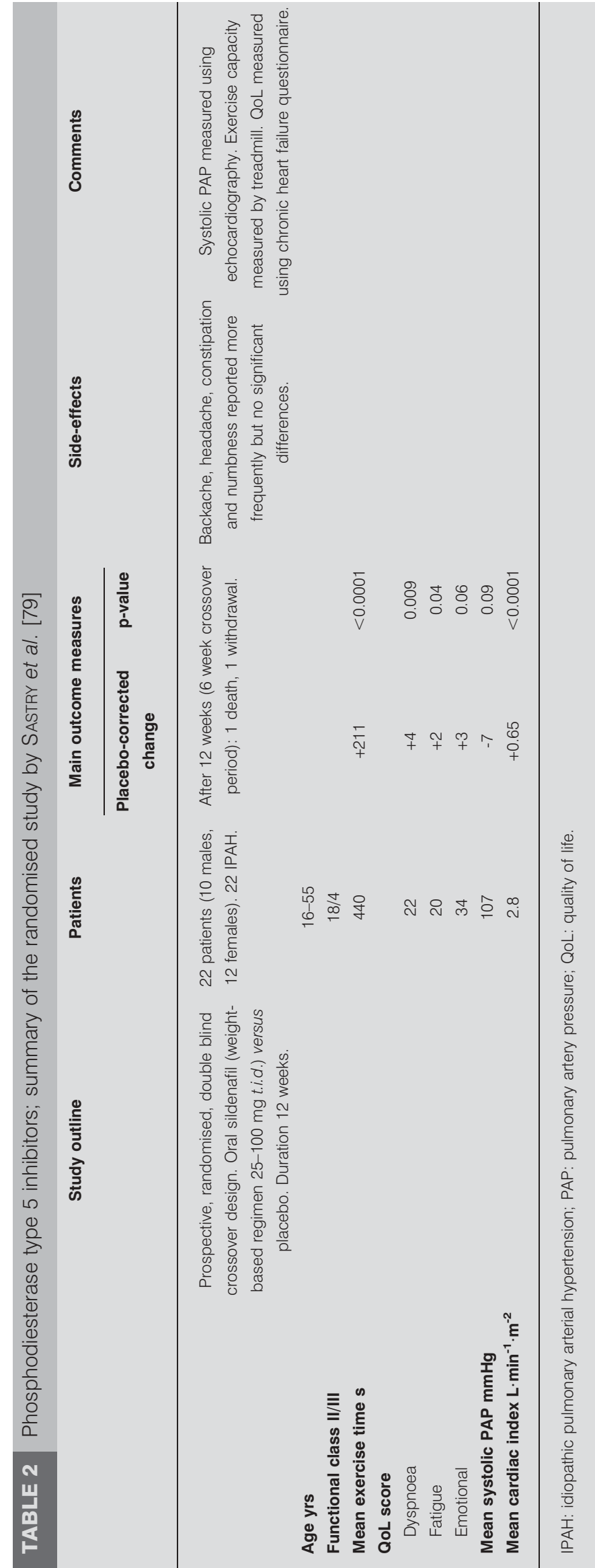

PAH treated either with placebo or oral sildenafil $(20,40$ or $80 \mathrm{mg}$ t.i.d.) for 12 weeks. The primary end-point was the change from baseline to week 12 in the 6-min walk test. All three doses of sildenafil improved exercise capacity (up to $50 \mathrm{~m}$ in the $80 \mathrm{mg}$ group, after correction for placebo), functional class and haemodynamics, compared with placebo-treated patients, and the drug was very well tolerated. The increase in the 6-min walk distance achieved after 3 months in the placebo-controlled phase was maintained in those patients who continued on openlabel treatment $(80 \mathrm{mg}$ t.i.d.). Based on these data, sildenafil $20 \mathrm{mg}$ t.i.d. was approved by the US Food and Drug Administration and the European Agency for the Evaluation of Medicinal Products in 2005 for the treatment of patients suffering from PAH. The approval of the lowest study dose was based on the flat (nonsignificant) dose-effect relationship between 20-80 $\mathrm{mg}$ t.i.d. for the primary end-point of the study.

The decision to license only the $20 \mathrm{mg}$ t.i.d. dose for $\mathrm{PH}$ has caused some difficulties for physicians managing these patients. First, the interaction with bosentan means that, in combination, the effective dose of sildenafil is halved and, therefore, below the approved treatment dose. The regulatory authorities have requested a further study of sildenafil using a lower dose, $10 \mathrm{mg}$ t.i.d., and a combination study with bosentan. Secondly, many physicians feel that, over time, with progression of the disease, the dose of sildenafil needs to be increased and a target dose of $50 \mathrm{mg}$ t.i.d. has been proposed [83]. In support of this, the $80 \mathrm{mg}$ t.i.d. dose did have a greater effect on pulmonary vascular resistance [81]. In addition, there remains an outstanding question as to whether t.i.d. dosing is required. This was based on plasma half-life of the drug, but there is evidence from some clinical and experimental settings that the duration of action of sildenafil might not be accurately reflected by plasma levels [84]. The increased affinity of sildenafil for PDE5 after intracellular phosphorylation of the enzyme, and the slow dissociation rate of sildenafil from the enzyme, could contribute to the flat doseeffect relationship $[40,85]$. Clearly, there is more to be done to define the best dose regimen for patients with $\mathrm{PH}$, as well as to determine the effect on survival.

Studies to establish the effect of sildenafil in combination with other drugs have been encouraging but are unblinded. The combination of sildenafil with bosentan is being used with increasing frequency, with reports of benefit (i.e. rescuing patients from deterioration) in the short term despite the concerns over pharmacokinetic interactions [86, 87]. The combination may be used without increasing hepatotoxicity from increasing plasma bosentan levels. Combination of sildenafil with sitaxentan or ambrisentan would have more predictable pharmacokinetics (as there is no clinically significant interaction) but no pharmacodynamic data from such combinations are currently available. Clinically, sildenafil has been combined with inhaled iloprost both acutely [72] and as long-term therapy [88], showing beneficial additive effects without increasing the side-effects of either agent. In the future, the combination of a PDE5 inhibitor and an agent that augments cGMP production may be therapeutically advantageous [73, 74].

Interestingly, sildenafil also seems to be effective for treating patients with $\mathrm{PH}$ associated with some other diseases. In patients suffering from HIV-related $\mathrm{PH}$, sildenafil was effective in reducing pulmonary vascular resistance $[89,90]$. Recent 


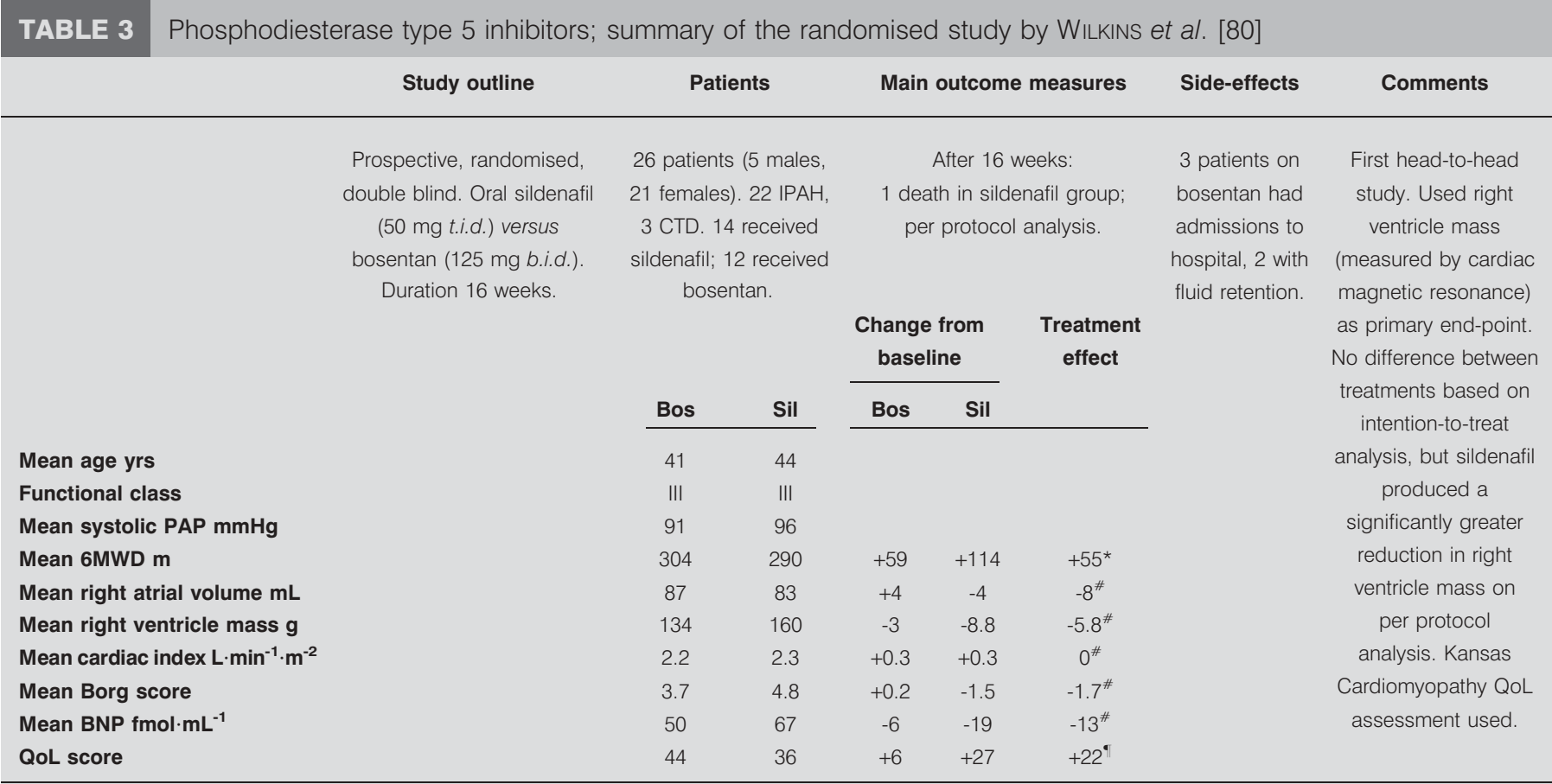

Bos: bosentan; Sil: sildenafil; IPAH: idiopathic pulmonary arterial hypertension; CTD: connective tissue disease; QoL: quality of life; 6MWD: 6-min walking distance; PAP: pulmonary arterial pressure; BNP: brain natriuretic peptide. ${ }^{*}$ : nonsignificant; " $p<0.002 ;{ }^{*} p<0.05$.

data also suggest that long-term oral sildenafil treatment is beneficial in patients with non-operable chronic thromboembolic $\mathrm{PH}[91,92]$.

\section{HYPOXIA-ASSOCIATED PH}

There is interest in the use of PDE5 inhibitors for the treatment of $\mathrm{PH}$ associated with hypoxia. An early study showed that a single oral dose of sildenafil $(50 \mathrm{mg})$ inhibited the acute pressor response to hypoxia (11\% inspired oxygen) in healthy volunteers [60]. To address this further, several studies have been conducted in subjects at altitude [93-95].

In one such study, systolic pulmonary artery pressure, cardiac output and peripheral arterial oxygen saturation were measured in 14 healthy mountaineers and trekkers at rest and during assessment of maximum exercise capacity on cycle ergometry, first while breathing a hypoxic gas mixture with $10 \%$ inspired oxygen at low altitude and secondly at high altitude (the Mount Everest base camp) [93]. Subjects were assigned sildenafil $50 \mathrm{mg}$ or placebo. Sildenafil treatment significantly reduced systolic pulmonary artery pressure at rest and during exercise in both scenarios, while increasing cardiac output and maximum workload.

Another study compared the effect of sildenafil $40 \mathrm{mg}$ t.i.d. for 6 days with placebo in 12 subjects housed at 4,350 m [94]. Treatment was started 6-8 h after arrival from sea level to high altitude. Systolic pulmonary artery pressure (measured by ECG) increased at high altitude before treatment (+29\% versus sea level) but normalised on sildenafil, while remaining elevated in the placebo group. Arterial oxygen tension was higher and alveolar-arterial difference in oxygen tension was lower on sildenafil than on placebo at rest and during exercise, and the altitude-induced decrease in maximal oxygen consumption was smaller on sildenafil. These data suggest that sildenafil protects against the development of altitude-induced $\mathrm{PH}$ and improves gas exchange, limiting the altitude-induced hypoxaemia and decrease in exercise performance.

One study has examined the effect of sildenafil in patients with $\mathrm{PH}$ living 2,500 $\mathrm{m}$ above sea level in the Kyrgyz Republic [96]. At 3 months, patients on sildenafil $25 \mathrm{mg}$ t.i.d. had a significantly lower mean pulmonary artery pressure (6.9 $\mathrm{mmHg}$ lower) at the end of the dosing interval than those on placebo. A similar effect was seen with sildenafil $100 \mathrm{mg}$ t.i.d. Both doses improved 6-min walk distance, the lower dose by $45.4 \mathrm{~m}$ and the higher dose by $40.0 \mathrm{~m}$.

It would be inappropriate to extrapolate from these studies to the treatment of $\mathrm{PH}$ associated with chronic obstructive pulmonary disease (COPD) and interstitial fibrosis. Nonetheless, there is interest in the use of PDE5 inhibitors in the management of these conditions. One concern with vasodilators in the presence of pulmonary disease is perturbation of ventilation-perfusion $\left(V^{\prime} / Q^{\prime}\right)$ matching. Nonspecific vasodilators can cause vasodilatation and increase perfusion of poorly ventilated alveoli, thereby reducing arterial oxygen saturation. There is some evidence that PDE5 inhibitors may preserve $V^{\prime} / Q^{\prime}$ matching [97]. Alveolar oxygenation is an important determinant of local NO production (and so of cGMP levels). Poorly ventilated areas of lung would be expected to have lower NO and cGMP levels and so the local effect of PDE5 inhibition would be less than in well-ventilated lung. In a randomised, controlled, open-label trial, in 16 
TABLE 4 Summary of Sildenafil Use in Pulmonary Arterial Hypertension (SUPER-1) study [81]

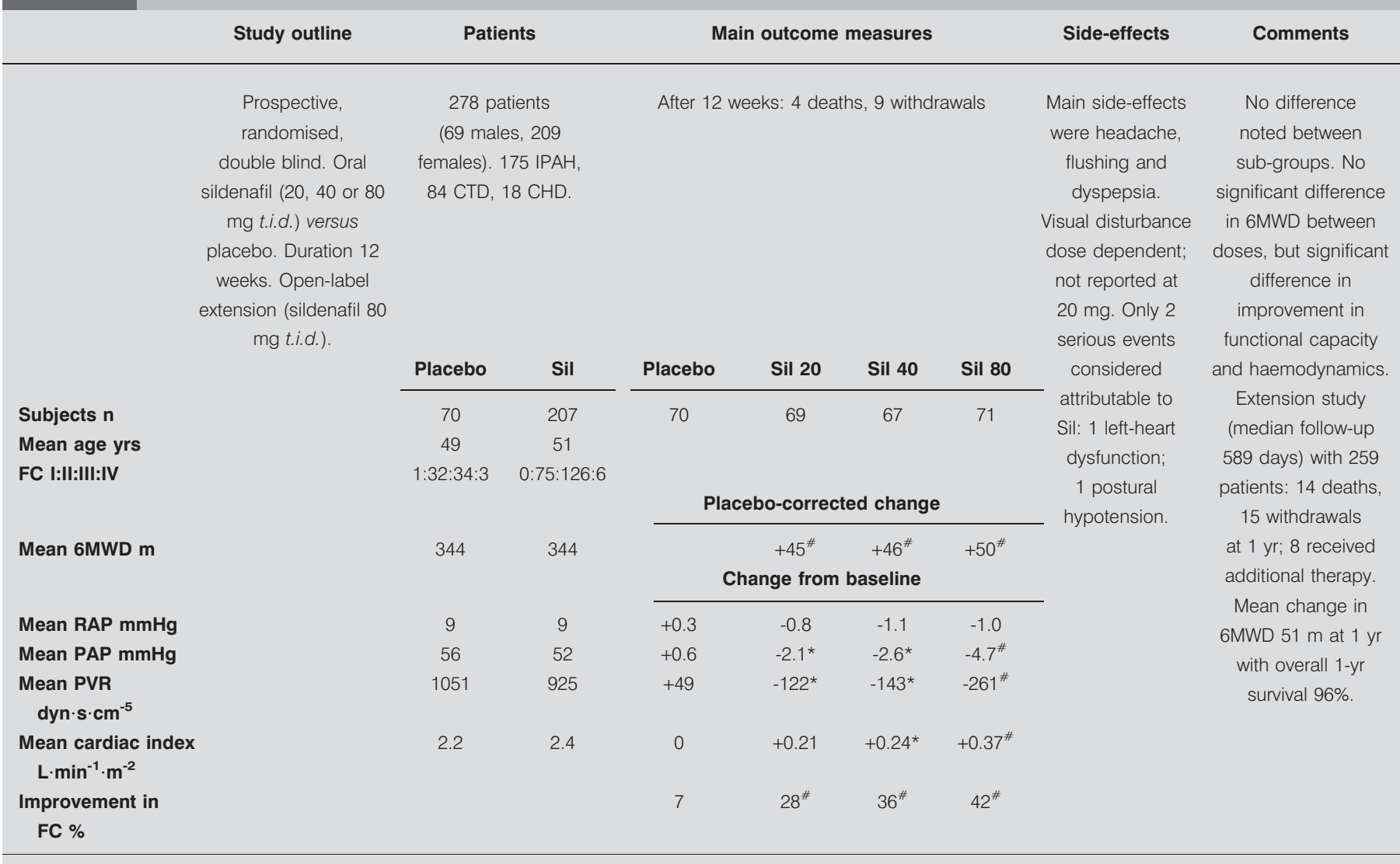

Sil: sildenafil; IPAH: idiopathic pulmonary arterial hypertension; CTD: connective tissue disease; CHD: congenital heart disease; 6MWD: 6-min walking distance; FC: functional class; RAP: right atrial pressure; PAP: pulmonary arterial pressure; PVR: pulmonary vascular resistance. ${ }^{*}: p \leqslant 0.001 ;$ *: $p<0.05$ versus placebo. No significant differences noted between dosage groups.

individuals with $\mathrm{PH}$ secondary to lung fibrosis, a single oral dose of sildenafil $50 \mathrm{mg}$ reduced the pulmonary vascular resistance index and improved $V^{\prime} / Q^{\prime}$ matching, as measured using multiple inert gas elimination. Shunt flow and perfusion of low $V^{\prime} / Q^{\prime}$ areas decreased under this agent, resulting in a significant increase in partial arterial pressure of oxygen [97].

The results of these studies have stimulated further investigations to address the therapeutic potential of sildenafil in patients suffering from chronic hypoxic pulmonary hypertension associated with COPD, interstitial lung disease and obstructive sleep apnoea [98-102]. In fact, very recent work supports the possibility of effective treatment of pulmonary hypertension in patients suffering from advanced COPD [102]. Based on the significant impact of COPD on public health, further definitive studies in this field are warranted.

\section{CONCLUSION}

The availability of orally active PDE5 inhibitors has added another dimension to the treatment of $\mathrm{PH}$. The data for sildenafil demonstrate clinically significant improvements in haemodynamic and exercise capacity over several months in patients with IPAH and $\mathrm{PH}$ associated with connective tissue disease and life at high altitude. The evidence base indicates that sildenafil is a first- or second-line treatment option for patients who present with IPAH in WHO class II and III. It may have a role in the treatment of other presentations of $\mathrm{PH}$ and as an add-on therapy, but patients who present in $\mathrm{WHO}$ class IV are best treated with a prostanoid.

Of great interest is the idea that PDE5 inhibition may differ from other available treatments for $\mathrm{PH}$ in two respects. One is the potential to reduce pulmonary vascular resistance without adversely affecting $V^{\prime} / Q^{\prime}$ matching, a property which would lend itself to the treatment of $\mathrm{PH}$ associated with lung disease. The second is the finding of PDE5 in the hypertrophied right ventricle of patients with $\mathrm{PH}$. A direct effect on the right ventricle which enhances contractility and cardiac output is a potentially valuable attribute, given the importance of right ventricular function as a determinant of prognosis in $\mathrm{PH}$.

However, care must be taken to avoid over-interpretation of existing data. Further studies are needed in order to examine these possibilities, and there is an urgent need for more information on long-term survival on sildenafil. A final word of caution: given that there are differences between phosphodiesterase type 5 inhibitors in their acute effects on the 
pulmonary circulation that may be related to their phosphodiesterase specificity, careful examination of the clinical effects of chronic treatment with each phosphodiesterase type 5 inhibitor is warranted.

\section{REFERENCES}

1 Fagan KA, Tyler RC, Sato K, et al. Relative contributions of endothelial, inducible, and neuronal NOS to tone in the murine pulmonary circulation. Am J Physiol 1999; 277: L472-L478.

2 Richards AM. Natriuretic peptides: update on peptide release, bioactivity, and clinical use. Hypertension 2007; 50: 25-30.

3 Piggott LA, Hassell KA, Berkova Z, Morris AP, Silberbach M, Rich TC. Natriuretic peptides and nitric oxide stimulate cGMP synthesis in different cellular compartments. J Gen Physiol 2006; 128: 3-14.

4 Lucas KA, Pitari GM, Kazerounian S, et al. Guanylyl cyclases and signaling by cyclic GMP. Pharmacol Rev 2000; 52: 375-414.

5 Münzel T, Feil R, Mülsch A, Lohmann SM, Hofmann F, Walter U. Physiology and pathophysiology of vascular signaling controlled by guanosine $3^{\prime}, 5^{\prime}$-cyclic monophosphatedependent protein kinase. Circulation 2003; 108: 2172-2183.

6 Rybalkin SD, Yan C, Bornfeldt KE, Beavo JA. Cyclic GMP phosphodiesterases and regulation of smooth muscle function. Circ Res 2003; 93: 280-291.

7 Omori K, Kotera J. Overview of PDEs and their regulation. Circ Res 2007; 100: 309-327.

8 Corbin JD, Turko IV, Beasley A, Francis SH. Phosphorylation of phosphodiesterase- 5 by cyclic nucleotidedependent protein kinase alters its catalytic and allosteric cGMP-binding activities. Eur J Biochem 2000; 267: 2760-2767.

9 Rybalkin SD, Rybalkina IG, Shimizu-Albergine M, Tang XB, Beavo JA. PDE5 is converted to an activated state upon CGMP binding to the GAF A domain. EMBO J 2003; 22: 469-478.

10 Zoraghi R, Bessay EP, Corbin JD, Francis SH. Structural and functional features in human PDE5A1 regulatory domain that provide for allosteric cGMP binding, dimerization, and regulation. I Biol Chem 2005; 280: 12051-12063.

11 Kotera J, Fujishige K, Imai $\mathrm{Y}$, et al. Genomic origin and transcriptional regulation of two variants of cGMPbinding cGMP-specific phosphodiesterases. Eur J Biochem 1999; 262: 866-873.

12 Lin CS, Chow S, Lau A, Tu R, Lue TF. Regulation of human PDE5A2 intronic promoter by cAMP and cGMP: identification of a critical Sp1-binding site. Biochem Biophys Res Commun 2001; 280: 693-699.

13 Fagan KA, McMurtry I, Rodman DM. Nitric oxide synthase in pulmonary hypertension: lessons from knockout mice. Physiol Res 2000; 49: 539-548.

14 Khoo JP, Zhao L, Alp NJ, et al. Pivotal role for endothelial tetrahydrobiopterin in pulmonary hypertension. Circulation 2005; 111: 2126-2133.

15 Leiper J, Nandi M, Torondel B, et al. Disruption of methylarginine metabolism impairs vascular homeostasis. Nat Med 2007; 13: 198-203.
16 Zhao L, Mason NA, Strange JW, Walker H, Wilkins MR. Beneficial effects of phosphodiesterase 5 inhibition in pulmonary hypertension are influenced by natriuretic peptide activity. Circulation 2003; 107: 234-237.

17 Quinlan TR, Li D, Laubach VE, Shesely EG, Zhou N, Johns RA. eNOS-deficient mice show reduced pulmonary vascular proliferation and remodeling to chronic hypoxia. Am J Physiol Lung Cell Mol Physiol 2000; 279: L641-L650.

18 Stamler JS, Loh E, Roddy MA, Currie KE, Creager MA. Nitric oxide regulates basal systemic and pulmonary vascular resistance in healthy humans. Circulation 1994; 89: 2035-2040.

19 Celermajer DS, Dollery C, Burch M, Deanfield JE. Role of endothelium in the maintenance of low pulmonary vascular tone in normal children. Circulation 1994; 89: 2041-2044.

20 Wharton J, Strange JW, Møller GM, et al. Antiproliferative effects of phosphodiesterase type 5 inhibition in human pulmonary artery cells. Am J Respir Crit Care Med 2005; 172: 105-113.

21 Girgis RE, Champion HC, Diette GB, Johns RA, Permutt S, Sylvester JT. Decreased exhaled nitric oxide in pulmonary arterial hypertension: response to bosentan therapy. Am J Respir Crit Care Med 2005; 172: 352-357.

22 Mason NA, Springall DR, Burke M, et al. High expression of endothelial nitric oxide synthase in plexiform lesions of pulmonary hypertension. J Pathol 1998; 185: 313-318.

23 Beall CM, Laskowski D, Strohl KP, et al. Pulmonary nitric oxide in mountain dwellers. Nature 2001; 414: 411-412.

24 Nagaya N, Nishikimi T, Uematsu M, et al. Plasma brain natriuretic peptide as a prognostic indicator in patients with primary pulmonary hypertension. Circulation 2000; 102: 865-870.

25 Leuchte HH, Holzapfel M, Baumgartner RA, et al. Clinical significance of brain natriuretic peptide in primary pulmonary hypertension. J Am Coll Cardiol 2004; 43: 764-770.

26 Andreassen AK, Wergeland R, Simonsen S, Geiran O, Guevara C, Ueland T. N-terminal pro-B-type natriuretic peptide as an indicator of disease severity in a heterogeneous group of patients with chronic precapillary pulmonary hypertension. Am J Cardiol 2006; 98: 525-529.

27 Pullamsetti S, Kiss L, Ghofrani HA, et al. Increased levels and reduced catabolism of asymmetric and symmetric dimethylarginines in pulmonary hypertension. FASEB J 2005; 19: 1175-1177.

28 Bulau P, Zakrzewicz D, Kitowska K, et al. Analysis of methylarginine metabolism in the cardiovascular system identifies the lung as a major source of ADMA. Am J Physiol Lung Cell Mol Physiol 2007; 292: L18-L24.

29 Kass DA, Takimoto E, Nagayama T, Champion HC. Phosphodiesterase regulation of nitric oxide signaling. Cardiovasc Res 2007; 75: 303-314.

30 Corbin JD, Beasley A, Blount MA, Francis SH. High lung PDE5: a strong basis for treating pulmonary hypertension with PDE5 inhibitors. Biochem Biophys Res Commun 2005; 334: 930-938.

31 Lin CS, Lau A, Tu R, Lue TF. Identification of three alternative first exons and an intronic promoter of human 
PDE5A gene. Biochem Biophys Res Commun 2000; 268: 596-602.

32 Nagendran J, Archer SL, Soliman D, et al. Phosphodiesterase type 5 is highly expressed in the hypertrophied human right ventricle, and acute inhibition of phosphodiesterase type 5 improves contractility. Circulation 2007; 116: 238-248.

33 Schermuly RT, Pullamsetti SS, Kwapiszewska G, et al. Phosphodiesterase 1 upregulation in pulmonary arterial hypertension: target for reverse-remodeling therapy. Circulation 2007; 115: 2331-2339.

34 Phillips PG, Long L, Wilkins MR, Morrell NW. cAMP phosphodiesterase inhibitors potentiate effects of prostacyclin analogs in hypoxic pulmonary vascular remodeling. Am J Physiol Lung Cell Mol Physiol 2005; 288: L103-L115.

35 Murray F, Patel HH, Suda RY, et al. Expression and activity of cAMP phosphodiesterase isoforms in pulmonary artery smooth muscle cells from patients with pulmonary hypertension: role for PDE1. Am J Physiol Lung Cell Mol Physiol 2007; 292: L294-L303.

36 Ghofrani HA, Osterloh IH, Grimminger F. Sildenafil: from angina to erectile dysfunction to pulmonary hypertension and beyond. Nat Rev Drug Discov 2006; 5: 689-702.

37 Blount MA, Beasley A, Zoraghi R, et al. Binding of tritiated sildenafil, tadalafil, or vardenafil to the phosphodiesterase-5 catalytic site displays potency, specificity, heterogeneity, and cGMP stimulation. Mol Pharmacol 2004; 66: 144-152.

38 Ballard SA, Gingell CJ, Tang K, Turner LA, Price ME, Naylor AM. Effects of sildenafil on the relaxation of human corpus cavernosum tissue in vitro and on the activities of cyclic nucleotide phosphodiesterase isozymes. J Urol 1998; 159: 2164-2171.

39 Turko IV, Ballard SA, Francis SH, Corbin JD. Inhibition of cyclic GMP-binding cyclic GMP-specific phosphodiesterase (Type 5) by sildenafil and related compounds. Mol Pharmacol 1999; 56: 124-130.

40 Corbin JD, Francis SH. Pharmacology of phosphodiesterase5 inhibitors. Int J Clin Pract 2002; 56: 453-459.

41 Gresser U, Gleiter $\mathrm{CH}$. Erectile dysfunction: comparison of efficacy and side effects of the PDE-5 inhibitors sildenafil, vardenafil and tadalafil - review of the literature. Eur J Med Res 2002; 7: 435-446.

42 Saenz de Tejada I, Angulo J, Cuevas P, et al. The phosphodiesterase inhibitory selectivity and the in vitro and in vivo potency of the new PDE5 inhibitor vardenafil. Int J Impot Res 2001; 13: 282-290.

43 Muirhead GJ, Rance DJ, Walker DK, Wastall P. Comparative human pharmacokinetics and metabolism of single-dose oral and intravenous sildenafil. $\mathrm{Br} J$ Clin Pharmacol 2002; 53: Suppl. 1, 13S-20S.

44 Nichols DJ, Muirhead GJ, Harness JA. Pharmacokinetics of sildenafil after single oral doses in healthy male subjects: absolute bioavailability, food effects and dose proportionality. Br J Clin Pharmacol 2002; 53: Suppl. 1, 5S-12S.

45 Walker DK, Ackland MJ, James GC, et al. Pharmacokinetics and metabolism of sildenafil in mouse, rat, rabbit, dog and man. Xenobiotica 1999; 29: 297-310.
46 Warrington JS, Shader RI, von Moltke LL, Greenblatt DJ. In vitro biotransformation of sildenafil (Viagra): identification of human cytochromes and potential drug interactions. Drug Metab Dispos 2000; 28: 392-397.

47 Hyland R, Roe EG, Jones BC, Smith DA. Identification of the cytochrome $\mathrm{P} 450$ enzymes involved in the $\mathrm{N}$-demethylation of sildenafil. Br J Clin Pharmacol 2001; 51: 239-248.

48 Ring BJ, Patterson BE, Mitchell MI, et al. Effect of tadalafil on cytochrome P450 3A4-mediated clearance: studies in vitro and in vivo. Clin Pharmacol Ther 2005; 77: 63-75.

49 Haynes J Jr, Kithas PA, Taylor AE, Strada SJ. Selective inhibition of cGMP-inhibitable cAMP phosphodiesterase decreases pulmonary vasoreactivity. Am J Physiol 1991; 261: H487-H492.

50 Braner DA, Fineman JR, Chang R, Soifer SJ. M\&B 22948, a cGMP phosphodiesterase inhibitor, is a pulmonary vasodilator in lambs. Am J Physiol 1993; 264: H252-H258.

51 Cohen AH, Hanson K, Morris K, et al. Inhibition of cyclic 3'-5'-guanosine monophosphate-specific phosphodiesterase selectively vasodilates the pulmonary circulation in chronically hypoxic rats. J Clin Invest 1996; 97: 172-179.

52 Zhao L, Mason NA, Morrell NW, et al. Sildenafil inhibits hypoxia-induced pulmonary hypertension. Circulation 2001; 104: 424-428.

53 Sebkhi A, Strange JW, Phillips SC, Wharton J, Wilkins MR. Phosphodiesterase type 5 as a target for the treatment of hypoxia-induced pulmonary hypertension. Circulation 2003; 107: 3230-3235.

54 Schermuly RT, Kreisselmeier KP, Ghofrani HA, et al. Chronic sildenafil treatment inhibits monocrotalineinduced pulmonary hypertension in rats. Am J Respir Crit Care Med 2004; 169: 39-45.

55 Itoh T, Nagaya N, Fujii T, et al. A combination of oral sildenafil and beraprost ameliorates pulmonary hypertension in rats. Am J Respir Crit Care Med 2004; 169: 34-38.

56 Clozel M, Hess P, Rey M, Iglarz M, Binkert C, Qiu C. Bosentan, sildenafil, and their combination in the monocrotaline model of pulmonary hypertension in rats. Exp Biol Med 2006; 231: 967-973.

57 Jackson G, Benjamin N, Jackson N, Allen MJ. Effects of sildenafil citrate on human hemodynamics. Am J Cardiol 1999; 83: 13C-20C.

58 Keating GM, Scott LJ. Vardenafil: a review of its use in erectile dysfunction. Drugs 2003; 63: 2673-2703.

59 Pomara G, Morelli G, Pomara S, et al. Cardiovascular parameter changes in patients with erectile dysfunction using PDE5 inhibitors: a study with sildenafil and vardenafil. J Androl 2004; 25: 625-629.

60 Kloner RA, Mitchell M, Emmick JT. Cardiovascular effects of tadalafil. Am J Cardiol 2003; 92: 37M-46M.

61 Webb DJ, Muirhead GJ, Wulff M, Sutton JA, Levi R, Dinsmore WW. Sildenafil citrate potentiates the hypotensive effects of nitric oxide donor drugs in male patients with stable angina. J Am Coll Cardiol 2000; 36: 25-31.

62 Thadani U, Smith W, Nash S, et al. The effect of vardenafil, a potent and highly selective phosphodiesterase- 5 inhibitor for the treatment of erectile dysfunction, on the cardiovascular response to exercise in patients with coronary artery disease. J Am Coll Cardiol 2002; 40: 2006-2012.

63 Curran M, Keating G. Tadalafil. Drugs 2003; 63: 2203 2212. 
64 Gori T, Sicuro S, Dragoni S, Donati G, Forconi S, Parker JD. Sildenafil prevents endothelial dysfunction induced by ischemia and reperfusion via opening of adenosine triphosphate-sensitive potassium channels: a human in vivo study. Circulation 2005; 111: 742-746.

65 Katz SD, Balidemaj K, Homma S, Wu H, Wang J, Maybaum S. Acute type 5 phosphodiesterase inhibition with sildenafil enhances flow-mediated vasodilation in patients with chronic heart failure. J Am Coll Cardiol 2000; 36: 845-851.

66 Hryniewicz K, Dimayuga C, Hudaihed A, et al. Inhibition of angiotensin-converting enzyme and phosphodiesterase type 5 improves endothelial function in heart failure. Clin Sci (Lond) 2005; 108: 331-338.

67 Rosano GM, Aversa A, Vitale C, Fabbri A, Fini M, Spera G. Chronic treatment with tadalafil improves endothelial function in men with increased cardiovascular risk. Eur Urol 2005; 47: 214-220.

68 Morganroth J, Ilson BE, Shaddinger BC, et al. Evaluation of vardenafil and sildenafil on cardiac repolarization. Am J Cardiol 2004; 93: 1378-83.

69 Ito M, Nishikawa M, Fujioka M, et al. Characterization of the isoenzymes of cyclic nucleotide phosphodiesterase in human platelets and the effects of E4021. Cell Signal 1996; 8: 575-581.

70 Dunkern TR, Hatzelmann A. The effect of sildenafil on human platelet secretory function is controlled by a complex interplay between phosphodiesterases 2, 3 and 5. Cell Signal 2005; 17: 331-339.

71 Berkels R, Klotz T, Sticht G, Englemann U, Klaus W. Modulation of human platelet aggregation by the phosphodiesterase type 5 inhibitor sildenafil. I Cardiovasc Pharmacol 2001; 37: 413-421.

72 Ghofrani HA, Wiedemann R, Rose F, et al. Combination therapy with oral sildenafil and inhaled iloprost for severe pulmonary hypertension. Ann Intern Med 2002; 136: 515-522.

73 Michelakis E, Tymchak W, Lien D, Webster L, Hashimoto K, Archer S. Oral sildenafil is an effective and specific pulmonary vasodilator in patients with pulmonary arterial hypertension: comparison with inhaled nitric oxide. Circulation 2002; 20: 2398-2403.

74 Klinger JR, Thaker S, Houtchens J, Preston IR, Hill NS, Farber HW. Pulmonary hemodynamic responses to brain natriuretic peptide and sildenafil in patients with pulmonary arterial hypertension. Chest 2006; 2: 417-425.

75 Wilkens H, Guth A, König J, et al. Effect of inhaled iloprost plus oral sildenafil in patients with primary pulmonary hypertension. Circulation 2001; 104: 1218-1222.

76 Ghofrani HA, Voswinckel R, Reichenberger F, et al. Differences in hemodynamic and oxygenation responses to three different phosphodiesterase-5 inhibitors in patients with pulmonary arterial hypertension: a randomized prospective study. J Am Coll Cardiol 2004; 44: 1488-1496.

77 PHIRST-1: Tadalafil in the treatment of pulmonary arterial hypertension. http://clinicaltrials.gov/show / NCT00125918 Date last updated: May 8, 2008.

78 Kothari SS, Duggal B. Chronic oral sildenafil therapy in severe pulmonary artery hypertension. Indian Heart $J$ 2002; 54: 404-409.
79 Sastry BK, Narasimhan C, Reddy NK, Raju BS. Clinical efficacy of sildenafil in primary pulmonary hypertension: a randomized, placebo-controlled, double-blind, crossover study. J Am Coll Cardiol 2004; 43: 1149-1153.

80 Wilkins MR, Paul GA, Strange JW, et al. Sildenafil versus endothelin receptor antagonist for pulmonary hypertension (SERAPH) study. Am J Respir Crit Care Med 2005; 171: 1292-1297.

81 Galiè N, Ghofrani HA, Torbicki A, et al. Sildenafil citrate therapy for pulmonary arterial hypertension. $N$ Engl J Med 2005; 353: 2148-2157.

82 Lewis GD, Shah R, Shahzad K, et al. Sildenafil improves exercise capacity and quality of life in patients with systolic heart failure and secondary pulmonary hypertension. Circulation 2007; 116: 1555-1562.

83 Garg N, Sharma MK, Sinha N. Role of oral sildenafil in severe pulmonary arterial hypertension: clinical efficacy and dose response relationship. Int J Cardiol 2007; 120: 306-313.

84 Moncada I, Jara J, Subira D, Castano I, Hernandez C. Efficacy of sildenafil citrate at 12 hours after dosing: reexploring the therapeutic window. Eur Urol 2004; 46: 357-360.

85 Mullershausen F, Friebe A, Feil R, Thompson WJ Hofmann F, Koesling D. Direct activation of PDE5 by cGMP: long-term effects within NO/cGMP signaling. J Cell Biol 2003; 160: 719-727.

86 Hoeper MM, Faulenbach C, Golpon H, Winkler J, Welte T, Niedermeyer J. Combination therapy with bosentan and sildenafil in idiopathic pulmonary arterial hypertension. Eur Respir J 2004; 24: 1007-1010.

87 Mathai SC, Girgis RE, Fisher MR, et al. Addition of sildenafil to bosentan monotherapy in pulmonary arterial hypertension. Eur Respir J 2007; 29: 469-475.

88 Ghofrani HA, Rose F, Schermuly RT, et al. Oral sildenafil as long-term adjunct therapy to inhaled iloprost in severe pulmonary arterial hypertension. J Am Coll Cardiol 2003; 42: 158-164.

89 Carlsen J, Kjeldsen K, Gerstoft J. Sildenafil as a successful treatment of otherwise fatal HIV-related pulmonary hypertension. AIDS 2002; 16: 1568-1569.

90 Schumacher YO, Zdebik A, Huonker M, Kreisel W. Sildenafil in HIV-related pulmonary hypertension. AIDS 2001; 15: 1747-1748.

91 Ghofrani HA, Schermuly RT, Rose F, et al. Sildenafil for long-term treatment of nonoperable chronic thromboembolic pulmonary hypertension. Am J Respir Crit Care Med 2003; 167: 1139-1141.

92 Reichenberger F, Voswinckel R, Enke B, et al. Long-term treatment with sildenafil in chronic thromboembolic pulmonary hypertension. Eur Respir J 2007; 30: 922-927.

93 Ghofrani HA, Reichenberger F, Kohstall MG, et al. Sildenafil increased exercise capacity during hypoxia at low altitudes and at Mount Everest base camp: a randomized, double-blind, placebo-controlled crossover trial. Ann Intern Med 2004; 141: 169-177.

94 Richalet JP, Gratadour P, Robach P, et al. Sildenafil inhibits altitude-induced hypoxemia and pulmonary hypertension. Am J Respir Crit Care Med 2005; 171: 275-281. 
95 Hsu AR, Barnholt KE, Grundmann NK, Lin JH, McCallum SW, Friedlander AL. Sildenafil improves cardiac output and exercise performance during acute hypoxia, but not normoxia. J Appl Physiol 2006; 100: 2031-2040.

96 Aldashev AA, Kojonazarov BK, Amatov TA, et al. Phosphodiesterase type 5 and high altitude pulmonary hypertension. Thorax 2005; 60: 683-687.

97 Ghofrani HA, Wiedemann R, Rose F, et al. Sildenafil for treatment of lung fibrosis and pulmonary hypertension: a randomised controlled trial. Lancet 2002; 360: 895-900.

98 Naeije R. Pulmonary hypertension and right heart failure in chronic obstructive pulmonary disease. Proc Am Thorac Soc 2005; 2: 20-22.
99 Higenbottam T. Pulmonary hypertension and chronic obstructive pulmonary disease: a case for treatment. Proc Am Thorac Soc 2005; 2: 12-19.

100 Voelkel NF, Cool CD. Pulmonary vascular involvement in chronic obstructive pulmonary disease. Eur Respir J 2003; 22: Suppl. 46, 28s-32s.

101 Barberà JA, Peinado VI, Santos S. Pulmonary hypertension in chronic obstructive pulmonary disease. Eur Respir J 2003; 21: 892-905.

102 Alp S, Skrygan M, Schmidt WE, Bastian A. Sildenafil improves hemodynamic parameters in COPD - an investigation of six patients. Pulm Pharmacol Ther 2006; 19: 386-390. 